\title{
Rupioid psoriasis on the hands
}

\author{
Pedro Jesús Gómez-Arias MD, Antonio José Vélez García-Nieto MD PhD
}

Cite as: CMAJ 2020 November 9;192:E1407. doi: 10.1503/cmaj.200517

A 42-year-old man with a history of psoriasis vulgaris was referred to our dermatology department with 6 weeks of worsening psoriasis. He had started treatment for bipolar disorder with valproic acid 4 months prior.

The patient had crusty, adherent plaques with reddish, sharply demarcated borders on the back of both hands (Figure 1). We diagnosed rupioid psoriasis based on the skin lesions and his history of psoriasis and valproic acid intake. Our differential diagnosis included secondary syphilis, histoplasmosis, scabies and HIV, all of which have been associated with similar lesions. ${ }^{1}$ His syphilis and HIV serology were negative. Our patient had responded well to methotrexate in the treatment of previous psoriatic flares; we prescribed methotrexate $15 \mathrm{mg} / \mathrm{wk}$. After 2 months, his lesions resolved completely and we began tapering the methotrexate (Figure 2). We discontinued it 4 months after his initial visit. He continued taking valproic acid.

The term "rupioid" (from the Greek rhupos, meaning filth) is used to describe oyster or limpet shell-shaped thick keratotic lesions. In contrast to rupioid forms, regular plaque-type psoriasis has a white, nonadherent and thin, scaly surface. Severe psoriatic flares and atypical forms of the disease (including rupioid plaques) have been reported in HIV-positive patients. ${ }^{2}$ Rupioid psoriatic flares have also been associated with drug treatments, such as oral or intravenous corticosteroids, nonsteroidal anti-inflammatory drugs, lithium carbonate, $\beta$-blockers or hydroxychloroquine, ${ }^{3}$ and we suspect valproic acid may have contributed to our patient's case. ${ }^{4}$ One report attributed a flare to oral steroid reduction. ${ }^{5}$

Patients with rupioid forms of psoriasis should have a careful drug history taken, along with HIV and syphilis testing. The relative benefits of intensifying psoriasis treatment (e.g., methotrexate, cyclosporine A, phototherapy, anti-tumour necrosis factor- $\alpha$, interleukin [IL]-23 or IL-17 monoclonal antibodies) versus withdrawal of triggering drugs should be evaluated, ideally with the help of a multidisciplinary team. ${ }^{4,6}$

\section{References}

1. Chung HJ, Marley-Kemp D, Keller M. Rupioid psoriasis and other skin disease with rupioid manifestations. Cutis 2014;94:119-21.

2. Queirós N, Torres T. HIV-associated psoriasis. Actas Dermosifiliogr 2018;109:303-11.

3. Balak DM, Hajdarbegovic E. Drug-induced psoriasis: clinical perspectives. Psoriasis (Auckl) 2017;7:87-94.

4. Gul Mert G, Incecik F, Gunasti S, et al. Psoriasiform drug eruption associated with sodium valproate. Case Rep Pediatr 2013;2013:823469.

5. Bonciani $D$, Bonciolini V, Antiga $E$, et al. A case of rupioid psoriasis exacerbated by systemic glucocorticosteroids. Int J Dermatol 2015;54:e100-2.

6. Kim GK, Del Rosso JQ. Drug-provoked psoriasis: is it drug induced or drug aggravated?: understanding pathophysiology and clinical relevance. J Clin Aesthet Dermatol 2010;3:32-8.

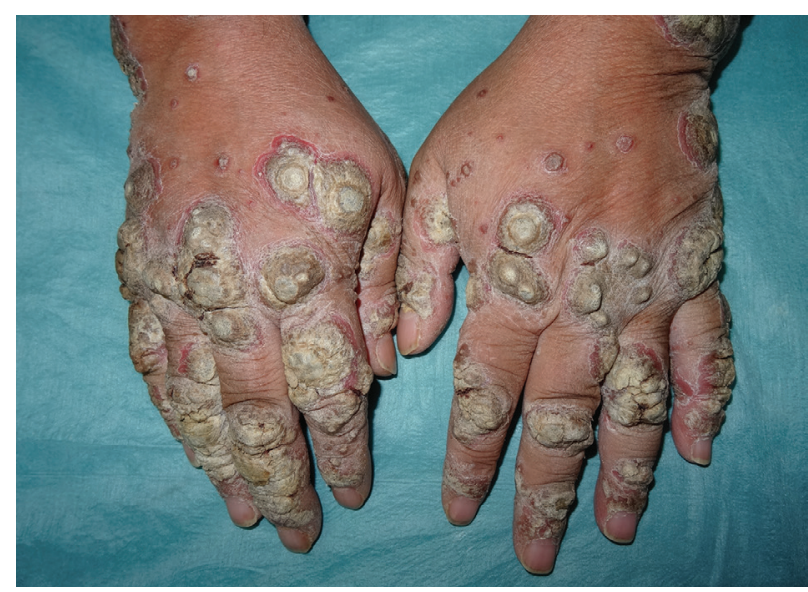

Figure 1: Crusty and adherent plaques on the back of the hands of a 42-year-old man. We diagnosed rupioid psoriasis.

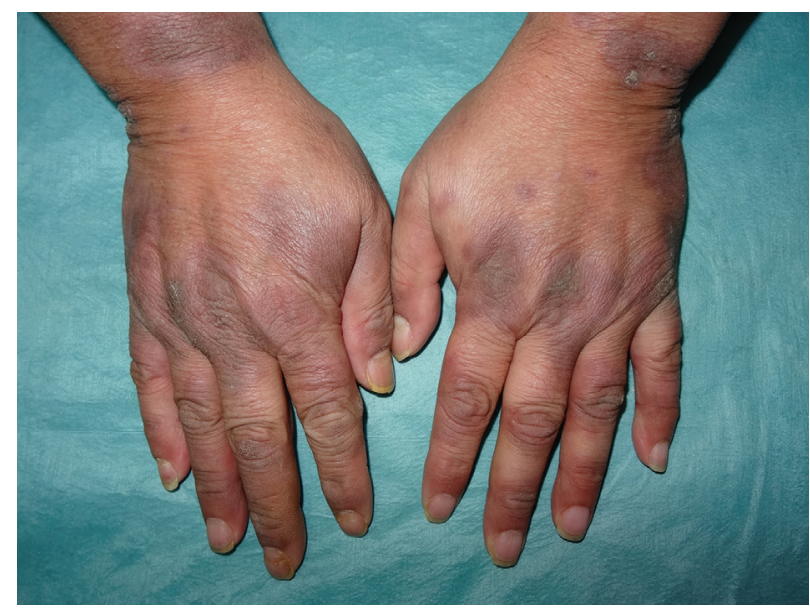

Figure 2: Complete resolution of the plaques was achieved after 2 months of treatment with methotrexate $15 \mathrm{mg} / \mathrm{wk}$. Postinflammatory hyperpigmentation can be seen.

\section{Competing interests: None declared.}

This article has been peer reviewed.

The authors have obtained patient consent.

Affiliation: UGC de Dermatología Médico-Quirúrgica y Venereología, Hospital Universitario Reina Sofía, Córdoba, Spain

Correspondence to: Pedro Gómez-Arias, pjga10@hotmail.com 